\title{
Family and Professional Pedagogy: the Overcome the Crisis of the Conjugal or Nuclear Family and the Search for a New Paradigm
}

\author{
Franco Blezza* \\ Department of Philosophical, Pedagogical and Economic-Quantitative Sciences DPPEQS of the University Gabriele d'Annunzio, Italy
}

*Corresponding author: Franco Blezza, Department of Philosophical, Pedagogical and Economic-Quantitative Sciences DPPEQS of the University Gabriele d'Annunzio, Italy

\begin{abstract}
The family that fulfils a paradigm defined "conjugal" or "nuclear" is a cultural construction resulting in the Enlightenment, the bourgeois revolutions at the end of XVIII century and in the end of the Age historiographic ally called "Modern". In the following brief historical age, characterized by a particular Bürgergeist, the family formed the nucleus of society, along with a product and a status of the system and its integrity, as well as a homologating pattern for education. The next epochal transitions began in the second half of the twentieth century and raised the issue of new paradigms of couple and family, thus requiring a renewed aid as essential to the Pedagogy as a social science and a profession. This paper bears witness to the contribution that pedagogy as a social profession takes and must be called to make to the family problems of the difficult and interminable epochal transition.
\end{abstract}

Keywords: Sozialpädagogik-Social Pedagogy; Bürgergeist; Family; Partnership; Parenthood; Professional Pedagogist

The Frenetic Cultural Evolution, and the A-Specific Educational Investment, in the Historical Nineteenth-Twentieth-Centuries Era

We must start with a terminological observation. In common speech, there are two meanings for the adjective "modern" and derivatives: one which follows the Latin etymology modum that is "way", in short, "fashionable"; and the other: one which draws on the Latin etymology modo that is "now", indicating the current; and the other which follows the Latin etymology modum that is "way", in short, "fashionable". Instead, in historiography, and therefore in the human sciences too, the word indicates a definite Age, after the Middle Age with a transition period, which covers roughly the XV, XVI and XVII centuries. Of course, among the other consequences, there is the not proper usage of the French term "postmoderne" and derivatives, which in fact had a fleeting success, and is not to be used in our context. This term, in fact, originated in the '70s, in Literature and then in Architecture, until Jean-Francois Lyotard (1925-1998) has conferred a certain philosophical dignity to it Lyotard [1]. An important question of terminology may be here of a scanty interest for us. Right, in fact, is the prefix "post", but it is quite wrong to assume that we live in an age that comes after the Modern Ages properly defined. The risk is not to deal with the next period, a very short one which began at the end of the '700, and went into an irreversible crisis of transition toward the second half of the '900, that is to say it covers near both the nineteenth and twentieth centuries culturally understood. It is the historical Bürgergeist Age, that we studied according to a pedagogical point of view Blezza [2] Blezza [3], also in account of its impact in the essential re-emergence of the profession of the Pedagogist and in the growing need for Pedagogy in society and culture Blezza[4,5]. We mean by this term that the bourgeoisie has taken all the power after the nobles and after the absolute sovereigns, but imitating styles of behaviour and inter-personal relationship of the nobles. From point of view of the Sozialpädagogik and the Professional Pedagogy, this last Age has seen an evolution social and cultural, scientific and technological, with an unprecedent pace, which were implemented through a very heavy investment in education, in a commitment of the educator and the human being who needs to be educated (educandum), product and condition of a particular socio-cultural reality, the reality in which the bourgeois class manages all the power and a frenetic evolution, trying to repeat and imitate the behaviour of nobles and Lords. In the middle there was a paradigm of family, which Emile Durkheim (1858-1917) suggested to call "conjugal" [orig. conjugale] family" Durkheim. Here he seems not to be only one among the fathers of the scientific Sociology, a major sociologist input giver to the Sozialpädagogik or 
Social Pedagogy, when it was still in its first ten-year periods as an independent branch of the Pedagogical Sciences. It must be taken in due consideration the fact that he was given the tenure of Pedagogy at the Sorbonne in 1906. Only in 1913 the name of the course will become "Pedagogy and Sociology", We have the well-founded conviction that his pedagogical works are not to be considered minor works [Durkheim works as exemplified, all available in the web. This educational investment was mostly a-specific: there was no need for great skills to be a good educator. The only requirement, enough for the most part, was to have been "educated" in turn, that is to have acquired the very principles of such an education, with a commitment to replicate them entirely and as closely as possible with one's own pupils. There was a substantial continuity between to be educated and being an educator. In recent decades the term "nuclear family" has prevailed. It was proposed by Pierre G. F. Le Play Le Play [6]. It should be noted that this paradigm of the family went into an irreversible and global crisis in recent decades, as all the cultural constructions typical of this historical period, or in other words, as what was called, properly, "the system" in the dispute which had origin in the second half of the '60s, and is commonly called "the Sixty-eight" Kurlansky [7].

\section{Education in the Age of the Bürgergeist}

\section{The dominant paradigm}

The dominant pedagogical paradigm suggested an education for homologation to a priori and indisputable models, thus being rigid, deterministic, mechanistic-oppressive and constraining, so that everyone could achieve a pre-determined role. These were models that tended to replicate the lordly behavior, more or less correctly and more or less realistically, and with the integration of models functional to the new society, in particular for the genres, the couple, and indeed the family. Edmond Demolins (1852-1907) summed all this culture and education over a century ago by stating that all education in that time was to find a good job, in case the pupil was a male, and to get a good marriage, in case she was a female Demolins $[8,9]$.

\section{Genders as Artifacts}

The genders were also built by a specific education: the aim was to maximize the polarizing asymmetry, so that each fulfills a very specific social role in every aspect, regardless of any subjective consideration. It is neither referring to asymmetry in reproductive physiology, nor to the consummation of sexuality, which are largely natural, but to the asymmetry in certain public roles determined by gender: the male, educated to be spent "outside" the couple, the family and the house; the female, to be spent in the same way, reciprocating the male "inside" these same realities. The male involved in the front, lightning, destructive, harmful attack outside himself, in short terms, involved in the expansion; the female devoted to understanding, to a winding action, to moving from her own field even suffering sacrifices, to the constraint of a total incorporation, and so forth Duby et Perrot [10]. All this, and all the other aspects of this extreme polarization that the reader can easily exemplify further, is not "natural": it is a cultural artifact. This is what Simone de Beauvoir meant when stating "On ne naît pas femme, on le devient." De Beauvoir [11].

\section{The "Respectability" As A New Concept}

An important aspect of this powerful kind of asymmetry was to omit to speak about everything that was linked with the practice of sexuality as a standard of living virtually without exception. No one can is allowed to talk of "certain things": even, or particularly, of what was going on inside the married couple and that was kept carefully stored, especially by women. This is, in essence, the criterion of bourgeois "respectability", which is different from "respect", and even from the right to be respected: "respectability" meant to act and behave without showing anything of someone's sexuality, of its exercise and enjoyment, so that it was clear that the subject had its full control. Such a criterion was considered unquestionable, essential for a civilized life: in general, its ownership was denied to foreigners, especially to those who were considered "racially" inferior: primarily to Jews in Central Europe, but also to Africans and even to the other natives of the colonies generally, often to the members of other nations. These peoples considered "different" would be subdue to a bestial, uncivilized, devilish instinct, which would lead them to ravish and brutalize women belonging to the "superior race", including female children. So, doing, they would have corrupted and "bastardized" that race sentencing its decline rather than its "due" dominion over the others. This is a very important topic, masterfully developed especially by George Mosse Mosse [12] but all the works of this author are very important in these specific subjects]. This reference will serve us a little further with regard to Nationalism, but by now we begin to understand what connection there was between an education based on a homologating model, the concept of respectability, and Nationalism itself. If we think about it, they are exactly the same prejudices that today extra communitarians are charged with males are all potential rapists of our women especially girls, while female are prostitutes by vocation, culture, race or being such at any extent since they are extra communitarian.

\section{The different instrumentality of sexual relationship and practice}

An instrumental view of sexuality and its practice descended from these reasons, and it was integrated with the other that we will see, moreover, with an instrumentality different from the male to the female. Neither sexuality nor the consummation of the sexual act were thought in their human essence, but how they could be used within the complex and (sincerely) delicate balance of the nuclear couple so of the family. It was believed that while consuming the male satisfied his own "natural" need, but it was not the same as for the female. The male, therefore, had to pay some price to the female, either in the couple and in the conjugal relationship or, at least, in any mercenary relationship. So, the female had to expect just the equivalent in another form, being not brought up to believe sex her own need, nor the satisfaction of this need, as essential as for the male even if in a different way. This vision of the practice of sexuality, like all the rest in the balance of the couple, involved heavy straining and unlimited sacrifices. But domestic intimacy, 
a cultural creation of the Evo, consistent with that Bürgergeist succeeded to hide everything. Today we would say that the practice of sexuality has no other purpose except the same persons who take sex. Obviously, it is a statement of principle: the conquest of the full essence of human sexuality is still to come.

\section{The birth and rise of Nationalism}

In that same period the concept of "nation" and Nationalism have risen and triumphed. As for the term "respectability", this Latin root began to be massively used as a noun and adjectivized, after the Bürgergeist Age gone, between the end of the eighteenth and the beginning of the nineteenth century. Before there were regions, states, kingdoms, empires, and even ethnic groups, peoples and cultures. With the bourgeois revolutions the ideas of "nation" and "national state" were built, to give educational homologation a broader basis and a clear political correspondence immediately recognizable. The practice to sexuality, or rather to "respectability" whether or not in the sense previously described is canonical and, in hindsight, it corresponds to the idea of a practice entirely instrumental Mosse 1987][12] The idea originally belonged to the Liberalism, the political "left" some century ago, as contrasted with the large supranational entity representing the modern state (characteristic of the Modern Age, that is absolute monarchies) or their direct continuation, as the Österreich (literally "Eastern Empire") or Hapsburg Empire, the Empire of the Czar and the Ottoman Empire. The program for free "nations" considered oppressed by entities that transcended the concept of nation, although today we tend to call them "supranational empires", belonged to the Liberalism as well, precisely the "left". It soon turned to the Right, both for the kind of rigid and oppressive culture and education that had generated, and because neither national minorities nor the regional peculiarities had the right to exist in the national state. As the contemporary Hans Magnus Enzesberger writes: "Clans and tribes exist since men have inhabited the earth, while the nations are only about two hundred years of existence", The nations and their behavioral consequences are a phenomenon typical of the Bürgergeist; as a matter of fact not surprisingly, Nationalisms have been built (mostly) in correspondence with the Hegelian thought in politics, and Romanticism in literature, music and other expressive arts, i.e. with their consistent ideologies and sometimes with the extreme features clearly characterizing that historic period. The German thinker adds: "The ethnic groups arise almost naturally, «by themselves»; on the contrary, the nations are deliberately created structures, often completely artificial which cannot disregard a specific ideology. This ideological basis, with its rituals and symbols (flags, hymns), was born only in the nineteenth century. Enzesberger 1992 [13]. Nationalisms had their triumph in the Great War, with the destruction of the Ottoman Empire and of the Österreich, but also of the Tsarist Empire as it was. It is remarkable that the state entities that were born from these dissolutions, Austria, Hungary, Turkey, have also adopted a nationalistic address; different, as it is known, was the evolution of the Tsarist Empire in the Union of Soviet Socialist Republics after a civil war that turned that massacre into a long and exacerbated conflict. This, among other things, would make us to reflect on the neo-nationalisms that exploded with the dissolution of the supra-national entities that had been left in Real Socialism, that is precisely the former Yugoslavia and the USSR. The terrible carnage of war Serb-Croat, Bosnian-Serb and Serbian-Kosovar (the first of the series, the Slovenian-Serb war, was understandably less bloody), and those between Russia and Chechenya, the one that did not dramatically explode in Russia and Georgia, now in Ukraine, should be a warning, if anything, should be taken as an example. Other neo-state formations, by the separation of the Czech Republic (with Prague as the capital) and Slovakia (with Bratislava), accomplished peacefully and by mutual agreement, and those that for now are only proposals for division of Belgium.

\section{The Paradigms of Couple and Family Corresponding to The Bürgergeist}

\section{A socio-cultural contextualization}

The way of referring to the genders and the practice of sexuality described above had its explicit part within well-defined paradigms of the family and, first, of the couple. These paradigms are an integral part of the Bürgergeist, and together they formed the core products of the eighth-twentieth century education, and the essential conditions for the maintenance of the entire sociocultural frame, or "system", The basis of the Western society has always been the family, his "cell". This awareness was not always followed by a similar awareness of the crucial importance, first of all, of the couple. In societies based on the patriarchal family, for example, the couple had less importance than it has still today. Therefore, generally speaking, a special care must be taken not so much for the family or couple in abstract, but for those particular types of family, first of all, the particular kind of couple, who were formed just after the bourgeois revolutions, and after their sociocultural changes and as a consequence to their functionality. At the basis of the eighth-twentieth century society there was, in fact, the couple, more than in other times in history and in other cultural realities. But it should be noted in preliminary terms that there was a couple and a family according to a particular paradigm, put in the context of that peculiar historical age.

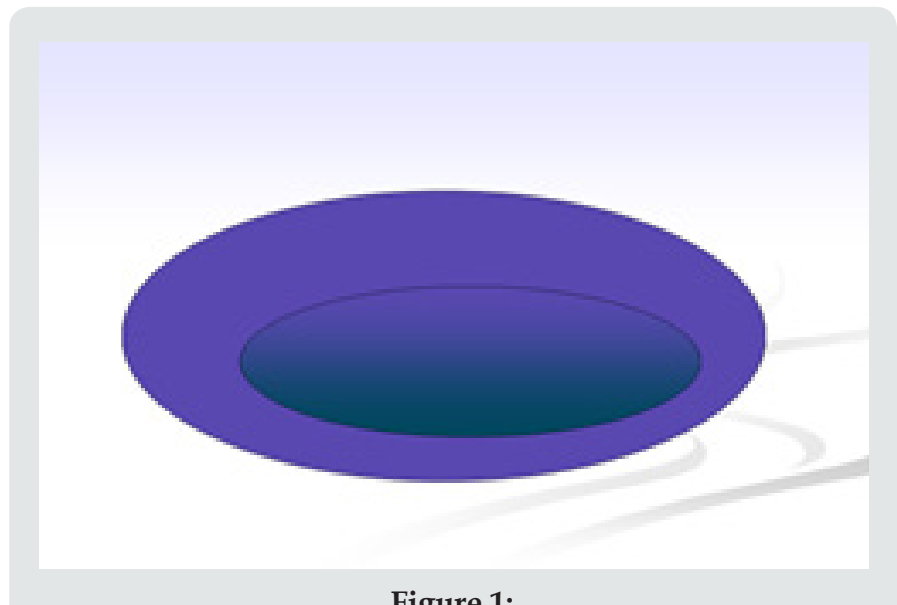

Figure 1: 
a) There was the overlapping couple: this was the direct consequence of the asymmetry brought to its extreme form, as outlined before. The female was melting, first of all, within the couple, and external relatedness important, "that mattered", was that of the male in the workplace as well as in the society, in culture as in politics and in everyday life. And there was also the nuclear or conjugal family itself (Figure 1).

b) Pay attention: they are not Venn diagrams; this is not Set Theory. In the nuclear family the sons where "hidden", "overlapped" by father and mother. From that couple and the family descended the nature of its cultural construction historically dated and contextualized, but remained unspoken: born in Western Europe between the late eighteenth and early nineteenth century with some important precedents in England a century before Trumbach [14], and the functional response historically contextualized into the new social demands and changes resulted from the production of the bourgeois revolutions Blezza [4]all but Part III contains discussions and treatment of cases and issues relevant to the topic Blezza [15], Blezza [5].

\section{Systematic contradictions with rhetorical purposes}

It was said that this couple and this family, that male and female gender, had "already" been existing or were "natural", but it was also said that they were "the result of centuries (or thousands) of civilization", and also that they were "traditional", These attributions taken alone were all false: they could not even be governed by a minimum of critical, cultural, historical, inquiry of Humanities and Social Sciences. But apart from these considerations that would require several pages of analysis, however we can immediately observe how they were mutually exclusive, and therefore their simultaneous use, which was also common, was hopelessly flawed by a systematic contradiction. We understand that this inconsistency, however, serious and incurable, could not be used in a social or educational intervention, except for a rhetorical function: the function of convincing those who received this message to straighten the new reality, without being able to decide on an informed basis. It was already known in ancient Greece as a contradictory theory could not have any cognitive value. In this sense, any systematical contradiction worked very well: the recipient of the message was put not in a position to know, he was rather the subject of an effective intervention that forced him to play pre-determined and hetero-direct roles and positions. It is understood that they were neither undetermined nor even direct the educators too: they did nothing but repeat to their pupils what they had received from his own educators. The only requirement that they had to possess, as it was said, and of course anyone understands, was to have been brought up in his turn.

\section{Parenting skills and responsibility: "a father knows", "a mother knows"}

A certain responsibility of parents in the education of children, to be formed with the best or worst "failure" of the same after the age of the development, can be found in many cultures and different historical periods, even if not in all. We would have some difficulties in this respect thinking about the Greek-traditional education, which took place almost in groups, in the case of males, with a declared component of pederasty. Or in the long history of abandonment of children, which in the Middle Ages and then in the Modern one took the form of oblation to some religious order and then the internment in special institutions (orphanages, children's homes), so that education was conducted often by the same orders Boswell [16]. A different talk still should be done about the patriarchal, medieval and modern family, in which the subjects in the age of development of all the clan were brought together by a single contact person, a female first and then a male, which was not necessarily the father or the mother of any of them. It is not so obvious or "natural" that parent is fully invested for the education of children, nor that they are responsible. This is an item for an overall reflection. Another factor to think about is "how" they practiced this responsibility. It is not said that the parent practices it directly: throughout the second millennium in the patrician family, for example, parents entrusted private tutors, teachers, officers, pedagogues, and other educational (Figures 2) to this task, not excluding (later) colleges and their operators. They, moreover, were not concerned to look after the children; ladies, for example were not used to breast-feeding their children, but gave them to a nurse, a dairy nurse too. This practice has manifested itself again in the twentieth century, albeit with decreasing frequency, however noble families and, consequently, the "milk nurses" have always been a minority phenomenon. This allows us to go to the specific of the past time, as there are some very important changes in this regard. They were about the responsibility of parents and their skills for everything that concerns both the care and the education of children in the age of the development: the first belonged to the mothers, although according to models of a male-centered society. This attribution is entirely arbitrary, devoid of any rationale, much less "natural", but that served to empower parents heavily, thus bringing them more likely to accept both the violence internal to the couple (especially the mothers) and that in the working world (especially for fathers) Mosse [17]. It was precisely the growing expertise required to educators in recent times, primarily to those family members, to take this assignment out, revealing its irrational nature.

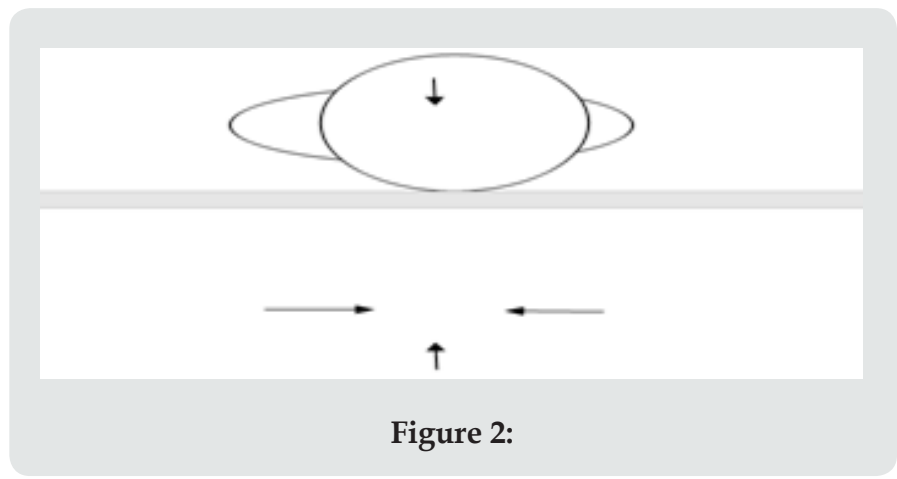

\section{The time frame of explicit education, necessarily short}

Education for approval to set patterns, and moreover practiced by people without any skill, had to last shortly, at least with regard 
to "explicit" education, declared as such. The reasons were different. Here it is sufficient to note that an education conducted by persons of no particular skills could not but be fundamentally "simple" and even rough, therefore it did not require long times but rather demanded not remote results; also the premise of a-priori models taken for "real" and not questionable demanded that education ended before these models, in the cultural in progress evolution, would, in turn, become unfeasible and not credible as obsolete.

In fact, in the past age education was expected to be accomplished in a decade, a dozen years or so: the age of the development, or parts thereof. In some pedagogical concepts, the children's ages were not, or only partially, included in it: education was certainly a strong act from childhood to adolescence, or part of it. Only in recent years we have begun to be fully aware of, and with dwindling reserves, education is for all human life. And we have started talking about "adult education" or "elderly" without too many reservations, as well as "education of second childhood" and "early childhood" without other distinctions that were not the ones that characterize the specificity of these as of any other age range.

\section{The epochal transition in the second half of the twentieth century}

The cultural, social, political, educational, cornerstones of the spent Ages are all gone in a progressive crisis with systematic recurrence, and with obvious consistency, in the second half of the twentieth century. This gives an idea of the new problems that are arising now: the contribution of professionals in specific educational culture is increasingly necessary and increasingly available. In our essays [2011, 2018] we have extensively dealt with the pedagogic profession and its emerging (or rather, re-emerging) needs in the same last decades. It should be duly added that the specific changes in this regard the Italian universities have known since the 90's are still largely unsuitable, inappropriate.

\section{Has "the family" gone into crisis?}

We talk a lot, particularly, of the "family crisis", and so simplistically, to make a healthy discernment difficult, difficult but perceived as a pedagogical duty. It is hard to deny that there is a crisis. If anything, the attention should be paid to the subject matter of this crisis. It is not the family as such. We say, rather, there is a crisis in a particular way of seeing the family: a particular paradigm of the family. And the symptoms of this crisis are manifest in a particularly obvious and often dramatic way, in the issue of women (in general, gender) and education of children. We should start by the criticism to a specific paradigm of family that is no longer adequate or if you prefer, is less and less suitable: It increasingly shows its inadequacies with regard to the education of children in today's society and, above all, in future perspective. In addition to the mentioned use of the technical term "nuclear family" or "conjugal family", one can call, alternatively, the family as "bourgeois" family, "private" family, "confidential" family, "Victorian" family, "early/ first industrial revolution" family, and in other ways, each of which identifies a unique character compared to the previously existing paradigms of family. Practically, we refer to that particular type of couple, first of all, and then the family, which arose in Western Europe after the Enlightenment, and together with the bourgeois revolutions [Trumbach], consolidated and spread in the nineteenth century, also on the tips of bayonets of Napoleon, and that has largely dominated the first half of the twentieth century and which began to show signs of irreversible crisis since the '50s and ' $60 \mathrm{~s}$. It is clear that we could also discuss the temporal characteristics in more precise terms, but it would be idle, if we thought that all the transitions are necessarily gradual and there were not a date before which a period of time goes first and the other comes after Ariès et Duby, Duby et Perrot [10].

\section{Transition and memory}

Each transition takes its time and its steps. Gradual transitions that cause the coexistence of phenomena attributable to different paradigms are going to survive for a long time: in this case, more different family paradigms, different family types than the eighthtwentieth century family. Faded to obsolescence and will of the women the already mentioned concept of "respectability", came progressively into a null the "domesticity", privacy and anything else covered and made more tolerable and more containable a series of dramas that are in fact exploded with the '50s, '60s and later criticized the family in which sexuality and its practice had a role mainly instrumental, the family that should be credited as if it were "always existed" found itself in crisis, of course, but not as the family an sich, rather than as a paradigm as a model, as a way of being and structuring.

Among other things, it has become more and more dramatically evident that parents, beyond their responsibilities in the upbringing of children, could not also be invested in its expertise. That middle-class family, and here is a point of emphasis for the other problematic issue, that of education of the female gender, was the family in which the roles were built so heavily skewed. What the family was requested by a changed social environment was that a powerful component of the most valuable and essential human resources was invested outside it, because there was the need for a new way of working, for the changing social, cultural, political, economic or whatever kind of relations. So then one of the two, the male, was brought to this outside investment: to give all his best outside the couple, outside the family, outside home. And the other, the female, was brought up to support him, to hold him up, with the same sacrifice to be spent within the couple, family, home [Ariès et Duby].

\section{Are nuclear families still a matter of fact?}

Are They? Definitely. Although no longer be predetermined for families as such, and instead they will be more and more the result of specific and deliberate choices. It is neither questionable that of the two, who spends outside is necessarily the male, nor that who spends more inside is necessarily (or "for her own nature") the female. There are many cases of neo-nuclear families, I have known, and I have been following professionally, in which the roles are exchanged seamlessly. And this, in itself, presents no particular 
problem. The only serious problems that I have found are belonging to the parents of these contractors, in particular to the male's parents, to his mother, who cannot accept the idea that her son is doing in his family home what she has always done as a female in her own.

\section{Family, educational issues and full knowledge of the facts}

Now, we must not think, for the fact that over two hundred years or so it was spoken very little about education with reference to family, and especially the fact that there was no talk of a professional intervention of Pedagogists about the family, that for it an investment in education was not required. On the contrary, to build those genders, and then to educate the prospective husband and wife, for the future father and mother, to build culturally "that" male and "that" female education was an investment, indispensable, and heavy. This was in relation to the particular Bürgergeist that animated that time society and therefore to the demand for human asymmetric expenditure of the two persons contracting the couple. The investment was powerful. The attainment of this asymmetry in education was highly demanding, and so crucial as to require a rhetorical device as heavy as the systematic contradiction. Virtue, in that pattern of education, meant to adjust to what was being proposed, not as examples, but as rigid, a-priori models, that had not to be discussed and for which the only possible virtue was homologation i.e. to repeat them as in the most faithful and unconditional way as possible. We will then understand what we have outlined before: that to be educators in that particular way of thinking did not require a specific skill, and even less a pedagogical skill. All that was required to a teacher so that he could be fully as such, in essence, was that he was brought up in his turn, in the sense of having acquired those models, those principles, those milestones, and then being available to replicate them for the generations to come. This way of thinking, in part, is still existent today. It makes us, on one hand, more problematic many educational situations referring to family, parenting, relationships. But it also allows us, on the other, to understand better what has changed and, therefore, to reflect on everything critically, retrospectively and advisedly. We do not need to take into account testimony and far away documentation, as if we were studying the education of the Greeks or the Romans, that yet would not be wrong. But we are talking about an education whose experience, in a way or another, in a very considerable extent, we all have within ourselves as a result.

Now, if in a not remote past, the investment in education was powerful, but it was so, for the reasons explained, an investment that did not require special skills in educators today, however, because we are dealing with a reality far complex, because the pace of evolution becomes more and more frantic, and in any case because that kind of couple and family is working less and less, being less and less adequate to deal positively with the problems which invest heavily family itself. Well, to be educators a specific skill is needed. And, increasingly, there may be the need or the opportunity of a professional help meant as a support, a professional ready to help in this so essential and so compelling function, for which family is not replaceable, reminding that the mere fact of being parents, does not mean to be able to carry it through. This is the reason why, everything considered, the support that the Pedagogist can give is an increasingly important contribution to understand the meaning of the couple, even before parenthood [Blezza 2015].

\section{The Full-Mutual Immersion Paradigm; Inadequate Alternative}

As a matter of fact, after the fall of the overlapping couple's social functioning, that for almost two centuries held very well, we wonder how one can suggest some alternative paradigm. For example, the full-mutual immersion paradigm shows to work even less than that of the overlapping couple Fromm [18] against the Sullivan theories and proposals, particularly and following] (Figure2). The discussion in this regard would be long. Let's just sum up how it is impractical because it tends to "burn" in it all the more valuable human resources, including those necessary for work and social life and, not infrequently, even for children. There could be also another condition, according to which such a pair appears equal but ends up, giving any license to the contractor who is the dominant character over the other. Other than that, similar partners claim to know what "true" love is, but the world around them is the reverse, dominated by hatred, interest and selfishness. The problem is that the two persons in question do not always have resources anymore. They believe to love each other but they practice selfishness in pair. On the contrary, true love spreads good feelings around, it does not scorch the earth.

\section{Alternative paradigms for couple and family}

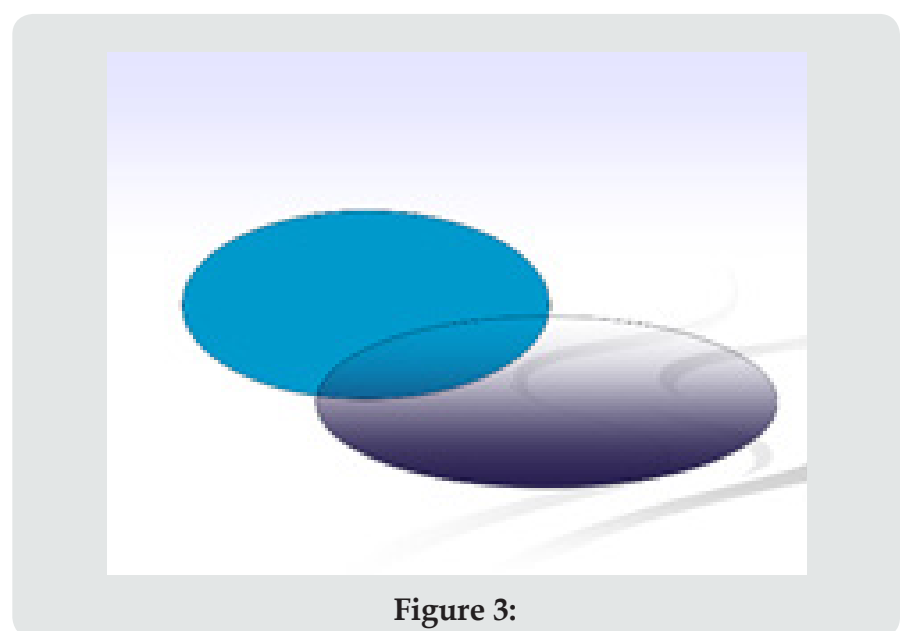

I think we can suggest as an alternative paradigm in our times, the so called bi-nuclear or intersection couple (Figure 3). According to this paradigm of the couple, there is no longer a severe gender asymmetry, which is manifested very well in different positions with respect to the couple's "inside" and "outside": "inside" and "outside" the family, "inside" and "outside" the house and so forth; but rather a tendency to symmetry in which the tasks are shared by mutual agreement between the two parties, between the two partners first and then parents. And while each one keeps its own sphere of relationships with the outside world, work, social relations, cultural, political activities are equally important to the 
one and the other. In fact, here there is no indication of which activities are suitable "for" the male or belong "to" the male, as the ones "for" or "to" the female. On this basis, they both set a common core: the true and proper intersection. In this sense, if we view the equality of functions, tasks, even with respect to relation with the outside world we can better understand what role the other subjects who belong to it can have within the family that is going to be formed around this couple, children in particular. But not only these. We are still talking of intersections. Similarly, we think that the various components of the family, have a part of everyone's life that is common to all the members, and then have a series of partial intersections with each of the other components: it is the idea of the poly-nuclear family, where each person and not the family as such is the nucleus. In the figure below I guess a fourmember family (Figure 4). We do not have to worry about the extension of this intersection because even couples or families with relatively little intersections work perfectly. We should rather be careful that every intersection is respected and that there will not be a sacrifice of the partial intersections in favor of a mythical omnipotence of the whole. It is not acceptable, for instance, that the desire for a stronger interaction between parents sacrifices partial intersections between both parents and children. What I mean is that what each parent, as a person develops individually with each child is to be respected and safeguarded. In the same way it is not to be admitted that the presence of children is also detrimental to the full development of intimacy between parents and whatever it involves. In this perspective, you can think much more constructively of a family enlargement. We could, for example, talk about the impact they will have in case of separation or divorce. But we would say now that in this case, into an intersection family, for example, other children can be accepted much better, and with less problems, than in a nuclear family. But also, an elder may have his/her own role in this family: that role which was in practice not easily attributed to him/her in the nuclear family, although many were the words equally misleading. We mean that the various partial intersections are always to be respected, without going to affect any sphere of autonomy.

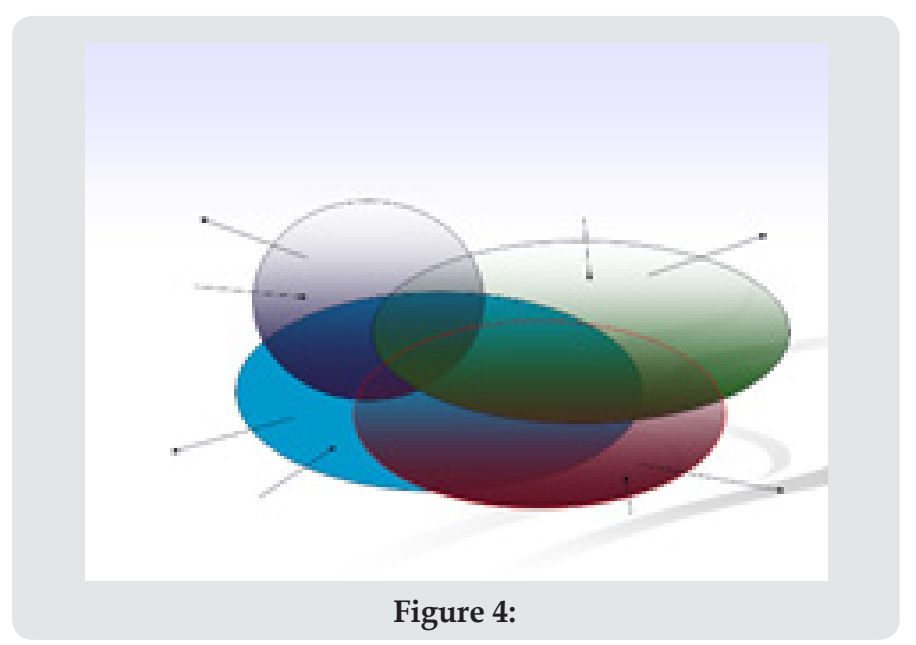

\section{Respecting Human Persons}

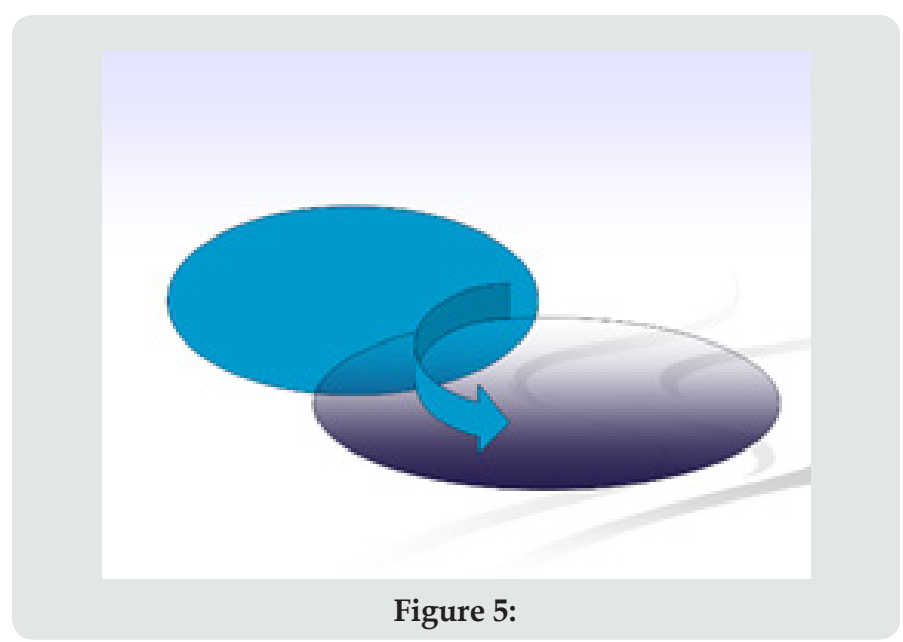

The intersection couple, and the poly-nuclear family, are also partnerships in which each of the contractors is respected as a more wholesome person. I explain it through a picture. Is it possible, within an intersection couple, that one of the two parties tries to disrupt the sphere of autonomy, that of the external relations belonging to the other? Of course, it is. But to do so, he or she must cross the common part (Figure 5). Therefore, he or she has to put into question, in danger, in possible crisis, what is already accepted as a common life. I have seen many couples to crash into a crisis for one of the part's claim to dominate the sphere of personal autonomy of the other: for the most part, in my experience, there is neither a justification for this, nor one of the partners feels the need to justify it. If, instead of two components, we have many more, there comes another possibility. Hereafter I just have drawn three of them (Figure 6). We could think of two parents and a son. Or two partners with a third partner who could be the father or the mother or another relative of one of the two persons (e.g. a university student far from home, or a temporary worker away from his parents), one of the two. In this case, if one of them, let's say the one shown on the left, is going to interfere with the autonomy of the other, let's suppose the one shown on the right, he can also do this without passing over the intersection between the two. That is, without jeopardizing what it has already been acquired as a common life. He can act through the third component, i.e. by using another family member as a means of blackmail, pressure on the partner. For example, one of the two parents can blackmail the other using the children. Or one of the two partners, blackmails the other by threatening the balance using a third one, maybe the old mother or father, or the young penniless closest relative of the other. As we can easily understand, just because we are aware of this possibility and of its drawbacks, the need for the professional aid of a Pedagogist is clearly put in evidence and outlined. We must warn in the strongest way parents or anyone else from doing so. Such a manipulation of one of the two partners admits no justifications although noble in goals or shareable in their nature. 
When, in Pedagogy, we say that the object of our intervention is the person, that the Pedagogist aims at people, we do not only want to introduce a technical term, perhaps to represent a difference between ourselves and other professionals. We mean that the other party for all of us is an individual who brings values, his own Lebenssinn, he is a political, social and cultural subject who is the core of a network of interpersonal communications. We must respect the person as such, an sich. So, any aim, however noble or shared we may never see a person as a means. Particularly, we could never admit that a child can be used as a tool. We then refuse to discuss the goal, alleged or real or fictitious: there is no object to justify the exploitation of the human being, especially if people are in need, weak and dependent.

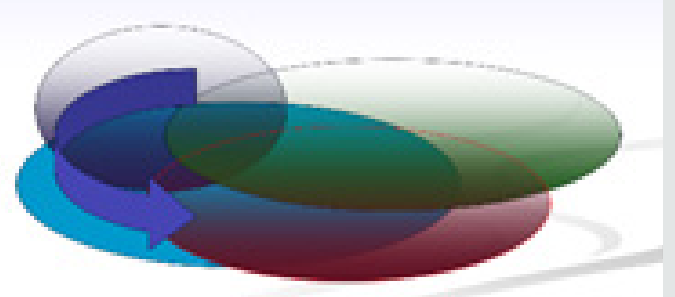

Figure 6:

\section{New Families, New Problems}

Of course, within the family, according to this paradigm, problems arise as they exist in every family. They are, above all, problems related to the couple and family's projects of life. Life projects that may not be entirely consistent. It may be that the two contractors are carrying out two projects of life at least in part contradictory: life projects that were contradictory originally, and which were not explicit enough in the aspects that collide, and that might have been taken for granted, as obvious, not requiring any further explanation. Each of the two partners, if you like him and her, has taken for granted something of the other that was not granted at all. And sooner or later this contradiction between the projects of life arises. It may also be that the projects of life, consistent in origin, have become increasingly incompatible, and sometimes on a collision course, because of personal evolution of one contractor or the other or even both. Over the years or decades paths of professional, cultural, political, social interest may open up which originally were not even thought. For example, one of the two, for a certain period of life, decides to set the professional, cultural, political commitment aside, to devote to their children while they are younger [19-23]. That this decision is final or not originally considered is of little importance, since as personal property it is unavailable. It could be her, and not too long ago would have taken for granted that it was her, but today we can say it is not said that it is her, and that it could be him, and it is him in a growing number of cases. As soon as these children are a little grown up, or even when they start going to the nursery, or kindergarten, he will take his professional, social, relational role back, revealing the temporary nature of the choice that the male partner had assumed to be permanent or, at least in the long run. They did not talk about these problems; they had no discussion on this matter. There was not enough dialogue. Beyond the professional experience of the writer, we must think that the professional and personal experience of anyone of us, can bring out the best evidence for the many aspects of life belonging to single life projects which have remained unspoken, not discussed, not explained, given as obvious, trivial, and taken for granted. "But I thought that she would feel at ease! ..."; "But I thought it was just a short-term choice! ...". And so on. It is a common occurrence, and please note that it does not concern the unconscious, rather a conscious way, yet not discussed, hidden, considered improperly to require neither investigation nor criticism, or even consideration. Thus, closing this brief exposure about the wide field of family Pedagogy, without concluding, rather opening it up, it is the dialogue that is not appropriate within the couple and the family today. The dialogue which was certainly not required in past times. But the inadequacy of today is a gap that should be absolutely bridged. The dialogue is not a discovery of the avant-garde Pedagogy of the twentieth or twenty-first century. Dialogue was proposed by Socrates roughly 2500 years ago, when Pedagogy was born, along with Philosophy and Western Civilization. The task that today's professionals of pedagogical culture are requested to fulfill has its origins there, at the core of the Western Civilization, in the ancient, classical Greece.

\section{References}

1. Lyotard, Jean François (1979) La condition postmoderne: rapport sur le savoir. Minuit, Paris.

2. Blezza, Franco (2007) Educazione XXI secolo. Pellegrini, Cosenza.

3. Blezza, Franco (2005) Studiamo l'educazione oggi - La pedagogia generale del nuovo evo. Osanna, Venosa-PZ.

4. Blezza, Franco (2011) Pedagogia della vita quotidiana. Pellegrini, Cosenza, nuova edizione completamente riveduta ed aggiornata.

5. Blezza, Franco (2018) Pedagogia professionale - Che cos'è, quali strumenti impiega e come si esercita. Libreria Universitaria, Limena PD.

6. Le Play PGF (1941) CEuvres de F Le Play: I Principes de paix sociale: La famille; II La Réforme de la société: Le travail, publiés sous la direction de Jacques et René Wittmann, Paris, Éditions d'histoire et d'art.

7. Kurlansky Mark (1968) 1968: The Year That Rocked the World. Random House USA, New York.

8. Demolins, Edmond (1897) À quoi tient la supériorité des Anglo-Saxons? Firmin-Didot, Paris. Disponible in ligne.

9. Demolins, Edmond (1901) L'éducation nouvelle: l'École des Roches. Firmin-Didot, Paris. Disponible in ligne.

10. Ariès, Philippe et Duby, Georges (responsables d'ensemble) (1985/87) Histoire de la vie privée en cinq volumes. Éditions du Seuil, Paris, Particulièrement Tome 4. De la Révolution à la Grande Guerre et Tome 5. De la Première Guerre mondiale à nos jours.

11. Beauvoir Simone de (1948) Le deuxième sexe. Librairie Gallimard, Paris.

12. Mosse George L (1987) Nationalismus und Sexualität. Rowohlt, Hamburg. 
13. Enzesberger Hans Magnus (1992) Die Große Wanderung. Dreiunddreißig Markierungen. Mit einer Fußnote über einige Besonderheiten bei der Menschenjagd. Suhrkamp Verlag, Frankfurt am Main.

14. Trumbach Randolph (1978) The Rise of the Egalitarian Family Aristocratic Kinship and Domestic Relations in Eighteenth-Century England. Academic Press, New York - San Francisco - London.

15. Blezza, Franco (2010) La pedagogia sociale - Che cos'è, di che cosa si occupa, quali strumenti impiega. Liguori, Napoli 2005, nuova edizione riveduta.

16. Boswell, John Eastburn (1988) The Kindness of Strangers: The Abandonment of Children in Western Europe from Late Antiquity to the Renaissance. Pantheon Books, New York.

17. Mosse George L (1996) The Image of Man. Oxford University Press, Oxford.
18. Fromm Erich (1956) The art of loving. Harper \& Row, New York.

19. Duby Georges, Perrot, Michelle (responsables d' ensemble) (1990-1991) Histoire des femmes en Occident en cinq volumes. Paris, Pion.

20. Durkheim Émile L'éducation morale (1902-1903) Cours de sociologie dispensé à la Sorbonne, Paris, Librairie Félix Alcan.

21. Durkheim, Émile (1938) (1904-1905) L'évolution pédagogique en France, Cours pour les candidats à l'Agrégation dispensé en. Paris, 1re édition, 3e trimestre

22. Durkheim Émile (1968) (1922 première édition) Éducation et sociologie, Paris, Les Presses universitaires de France.

23. Durkheim Émile (1924) Sociologie et Philosophie, Paris, Librairies Félix Alcan.

\section{(C) This work is licensed under Creative}

To Submit Your Article Click Here: Submit Article

DOI: $10.32474 /$ RRHOAJ.2019.04.000188

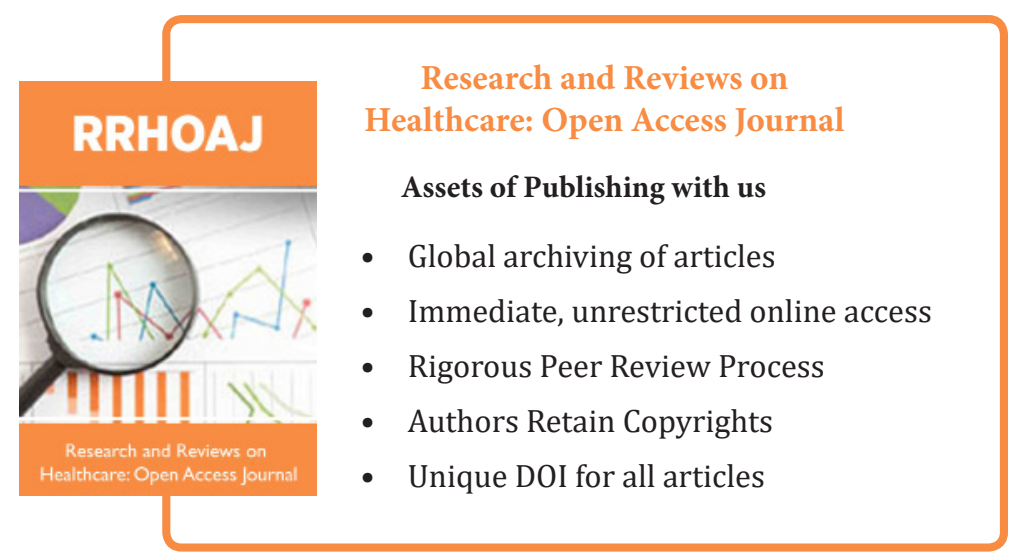

